\title{
Homeodomain transcription factor NKX2.2 functions in immature cells to control enteroendocrine differentiation and is expressed in gastrointestinal neuroendocrine tumors
}

\author{
Yu-Cheng Wang ${ }^{1,2}$, Emerick Gallego-Arteche ${ }^{1,2}$, Gioia lezza ${ }^{3}$, Xiaochen Yuan ${ }^{1,2}$, \\ Mary $R$ Matli ${ }^{1}$, Su-Pin Choo ${ }^{1,4}$, Marlene B Zuraek ${ }^{1,2}$, Ravi Gogia ${ }^{1,2}$, \\ Francis C Lynn ${ }^{5}$, Michael S German ${ }^{4,5}$, Emily K Bergsland ${ }^{1,4}$, \\ David B Donner ${ }^{1,2}$, Robert $S$ Warren ${ }^{1,2}$ and Eric K Nakakura' ${ }^{1,2}$
}

\footnotetext{
${ }^{1}$ UCSF Helen Diller Family Comprehensive Cancer Center, Departments of ${ }^{2}$ Surgery, ${ }^{3}$ Pathology, and ${ }^{4}$ Medicine, University of California, San Francisco, California 94143, USA

${ }^{5}$ Hormone Research Institute, Diabetes Center, University of California, San Francisco, California 94143, USA
}

(Correspondence should be addressed to E K Nakakura at Division of Surgical Oncology, Department of Surgery, UCSF Helen Diller Family Comprehensive Cancer Center, 1600 Divisadero Street, A-724, San Francisco, California 94143-1932, USA; Email: eric.nakakura@ucsfmedctr.org)

\begin{abstract}
The homeodomain transcription factor NKX2.2 is necessary for neuroendocrine (NE) differentiation in the central nervous system and pancreas. NE tumors derived from the gut are defined by their NE phenotype, which is used for diagnosis and contributes to tumorigenicity. We hypothesized that NKX2.2 is important for NE differentiation in normal and neoplastic gut. NKX2.2 and NE marker expression was investigated in the small intestine of embryonic and adult mice using immunofluorescence (IF). To determine the role of NKX2.2 in NE differentiation of the intestine, the phenotype of $N k \times 2.2(-/-)$ mice was examined by IF and real-time (RT)-PCR. NKX2.2 and NE marker expression in human NE tumors of the gut and normal tissues were evaluated by immunohistochemistry and qRT-PCR. NKX2.2 expression was detected in the intervillus/crypt regions of embryonic and adult mouse intestine. Co-expression of Nkx2.2 with neurogenin3 (NEUROG3) and hormones was observed in the adult intestinal crypt compartment, suggesting NKX2.2 functions in NEUROG3-positive endocrine progenitors and newly differentiated endocrine cells. In the intestine of $N k \times 2.2(-/-)$ mice, we found a dramatic reduction in the number of cells producing numerous hormones, such as serotonin, gastrin, cholecystokinin, somatostatin, glucagon-like peptide 1 (GLP-1), and secretin, but an increase in cells producing ghrelin. NKX2.2 was expressed in most (24 of 29) human NE tumors derived from diverse primary sites. We conclude NKX2.2 functions in immature endocrine cells to control NE differentiation in normal intestine and is expressed in most NE tumors of the gut, and is therefore a novel target of diagnosis for patients with gastrointestinal NE tumors.
\end{abstract}

Endocrine-Related Cancer (2009) 16 267-279

\section{Introduction}

The incidence of neuroendocrine (NE) - or carcinoid tumors has increased over the past 25 years, occurring in $\sim 38.5$ individuals/million in the USA (Maggard et al. 2004, Modlin et al. 2008). The gastrointestinal (GI) tract is the predominant site of origin for NE tumors, which frequently metastasize. At diagnosis, most patients with GI NE tumors are not candidates 
for surgery, the only potentially curative treatment, due to the presence of extensive metastatic disease (Modlin et al. 2008). NE tumors are defined by their NE phenotype, which is used for diagnosis and contributes to tumor-related morbidity and mortality. Detection of the NE marker chromogranin A $(\mathrm{CgA})$ is used to diagnose NE tumors. Serotonin (5-HT) and other mediators cause debilitating symptoms and stimulate NE tumor growth (Ishizuka et al. 1992, von Wichert et al. 2000). Current therapy is ineffective in palliating symptoms long-term and has little activity in shrinking tumors (Nakakura et al. 2007). More effective therapies and earlier diagnosis are needed but require a better understanding of $\mathrm{NE}$ tumor biology.

NE tumors are thought to arise from endocrine cells of the gut - the largest endocrine organ in the body (Creutzfeldt 1994). The gut produces more than $100 \mathrm{GI}$ hormones that play important roles in intestinal motility, secretion, inflammation, pain, appetite regulation, and neoplasia (Rehfeld 1998). In the small intestine, endocrine cells and the three other main cell types (enterocytes, goblet cells, and Paneth cells) arise from multipotent stem cells located in the crypt compartment (Schonhoff et al. 2004a). Every 3-4 days, endocrine cells turn over as newly differentiated cells migrate from the crypt to the villus tip and are extruded into the gut lumen.

Very little is known about how a gut stem-cell becomes a hormone-producing endocrine cell. Only a handful of transcription factors are known to regulate NE differentiation in mouse small intestine (Schonhoff et al. 2004a). One factor, neurogenin3 (NEUROG3), initiates NE differentiation in immature cells (Jensen et al. 2000a, Jenny et al. 2002, Lee et al. 2002, Schonhoff et al. 2004b). Subsequent genes that promote formation of hormoneproducing cells in the intestine include PAX4, PAX6, and NEUROD1, but other genes are likely to be involved (Schonhoff et al. 2004a). Many of the same transcription factors function during NE differentiation in various contexts, including central nervous system and gut development (Schonhoff et al. 2004a), and in neoplastic tissue (Borges et al. 1997, Nakakura et al. 2001, 2005). For many years, the homeodomain transcription factor NKX2.2 has been known to be important for NE differentiation in the central nervous system and pancreas (Sussel et al. 1998, Briscoe et al. 1999, Cheng et al. 2003, Craven et al. 2004, Pattyn et al. 2004). A recent study showed that a transgenic zebrafish line with EGFP driven by the $N k x 2.2 a$ locus identifies endocrine cells in the intestine ( $\mathrm{Ng}$ et al. 2005). We hypothesized that NKX2.2 is important for NE differentiation in normal and neoplastic gut.

\section{Materials and methods}

\section{Animals and human tissues}

$N k x 2.2$ mutant mice were generated, maintained, and genotyped as previously described, according to the regulations of the IACUC at the University of California, San Francisco (Sussel et al. 1998). Human tissue samples were obtained from resection specimens in the UCSF Pathology Department after approval by the Committee on Human Research.

\section{Histology and immunohistochemistry}

Tissues were fixed in Z-fix (Anatech, Battle Creek, MI, USA) and processed for paraffin sections (Sussel et al. 1998). The following primary antibodies were used: mouse monoclonal anti-NKX2.2 (Developmental Studies Hybridoma Bank), 1:25; rabbit anti-NEUROG3, 1:2000 (Michael German); rabbit anti-gastrin/ cholecystokinin (CCK), which reacts with gastrin and CCK as they share a common carboxy-terminal tetrapeptide sequence that is necessary for bioactivity, (Novocastra, Newcastle, UK), 1:200; goat anti-ghrelin (Santa Cruz, CA, USA), 1:800; rabbit anti-CgA (Immunostar, Hudson, MA, USA), 1:1000; rabbit antiGLP1 (Peninsula), 1:200; rabbit anti-secretin (Phoenix, Belmont, CA, USA), 1:1000; rabbit anti-serotonin (Immunostar), 1:4000; mouse monoclonal anti-serotonin (Dako, Carpinteria, CA, USA), 1:25; rabbit antisomatostatin (Dako), 1:200; rabbit anti-cleaved caspase-3 (Cell Signaling, Danvers, MA, USA), 1:125; mouse monoclonal anti-MKI67 (Novocastra), 1:100. Secondary antibodies (Jackson ImmunoResearch) were FITC-conjugated goat anti-mouse and anti-rabbit, 1:200; FITC-conjugated donkey anti-goat and antimouse, 1:200; Cy3-conjugated donkey anti-goat, and goat anti-mouse and anti-rabbit, 1:400. Biotinylated secondary antibodies (Vector, Burlingame, CA, USA) were detected with the ABC Elite immunoperoxidase system (Vector). Alcian blue staining of goblet cells was done according to manufacturer's instructions (Poly Scientific). Enterocyte differentiation was assessed by FITC-conjugated wisteria floribunda agglutinin (WFA) lectin staining (Vector Labs). Slides were imaged on an Axioskop 2 microscope (Zeiss, Thornwood, NY, USA) or on an LSM510 META confocal microscope (Zeiss).

\section{Cell quantitation and data analysis}

Multiple sections from the small intestine (duodenum) from at least $3 N k x 2.2(+/+)$ and $N k x 2.2(-/-)$ mice were analyzed for each experiment. The number of cells per unit length of intestine was calculated for at least 
three different mice for each genotype and a minimum of $30 \mathrm{~mm}$ of intestinal length was analyzed per animal. Results are expressed as mean \pm s.E.M. Mean changes were compared using the $t$-test. A value of $P<0.05$ was considered to be statistically significant.

Immunohistochemical analysis of antigen expression levels in human tissues was based on the number of positively stained tumor cells divided by the total number of tumor cells to calculate the percentage. Tumor cells were distinguished from normal cells based on H\&E staining: monomorph cytology, rare mitoses, low atypia, and growth pattern (i.e. glandular, trabecular, insular, undifferentiated, or mixed; Kulke \& Mayer 1999). Numeric scores were based on the percentage of positive tumor cells: $0(<5 \%)$, 1 (5-25\%), 2 (26-50\%), 3 (51-75\%), 4 (>75\%).

\section{RNA analysis}

Total RNA was isolated with the RNeasy Mini Kit (Qiagen) from the indicated tissues. First-strand cDNA was prepared from $1 \mu \mathrm{g}$ total RNA with the SuperScript III first-strand cDNA synthesis system (Invitrogen) and a combination of random hexamer and oligo dT primers. For TaqMan real-time (RT)-PCR amplification, $30 \mathrm{ng}$ cDNA template was used. The quantity of cDNA template was determined based on the concentration of RNA used for cDNA synthesis measured by spectrophotometer. All primer/probe sets were validated with a standard curve using serial cDNA dilutions. All assays were performed with ABI assay-on-demand and ABI TaqMan Universal PCR Master Mix. Quantification was done with an Opticon2 thermocycler (MJ Research, Waltham, MA, USA) following the manufacturer's instructions. Results were normalized relative to the level of mouse Gus $2 b$ mRNA, which was used as an internal control for cDNA quantity and quality. For RT-PCR analysis the following primers were used: gastrin, $5^{\prime}$-gtgtgtgtgcatgctagtcttag- $3^{\prime}$ and $5^{\prime}$-gcgaccaaagtccatccatccg- $3^{\prime}$; CCK, $5^{\prime}$-acatccagcaggtccgcaaag- $3^{\prime}$ and $5^{\prime}$-cgatgggtattcgtagtcctc- $3^{\prime}$; secretin, $5^{\prime}$-gacgttcaccag cgagctcag- $3^{\prime}$ and $5^{\prime}$-cactctgaatggtcgacagca- $3^{\prime}$; somatostatin, $5^{\prime}$-tctctgctgcctgcggacct- $3^{\prime}$ and $5^{\prime}$-gccaagaagtacttggccagttc- $3^{\prime}$; glucagon, $5^{\prime}$-atcattcccagcttcccaga- $3^{\prime}$ and $5^{\prime}$-aggttcctcttggtgttcat- $3^{\prime} ;$ Tacl, $5^{\prime}$-cgcaatgcagaactacgaaa- $3^{\prime}$ and $5^{\prime}$-gcttggacagctccttcatc- $3^{\prime}$; and Gapdh, 5'-caaaatggtgaaggtcggtgt- $3^{\prime}$ and $5^{\prime}$-ttctccatggtggtgaagaca- $3^{\prime}$. The following TaqMan Gene Expression Assay probes (Applied Biosystems, Foster City, CA, USA) were used: GusB, Mm00446953_m1; Nkx2.2, Mm00839794_m1; TPH-1, Mm00493794_m1; Ghrelin, Mm00445450_m1.

\section{Results}

NKX2.2 is expressed in immature endocrine cells of embryonic and adult mouse small intestine

To first ascertain whether NKX2.2 is involved in gut NE differentiation, we evaluated NKX2.2 expression in embryonic and adult mouse proximal small intestine (duodenum) by immunofluorescent (IF) analysis. The proximal small intestine contains a variety of gut endocrine cell types, which arise from pluripotent stem cells in the intervillus/crypt regions and occupy characteristic locations along the crypt-villus axis (Wilson \& Radtke 2006). Endocrine cells in mice can be detected starting on embryonic day (E) 9.5 in the pancreas and on E15.5 in the small intestine (Schwitzgebel et al. 2000, Jenny et al. 2002).

Coincident with the appearance of $\mathrm{CgA}$ - and 5-HT-positive cells in the intestine at E15.5, we detected NKX2.2 expression in intervillus regions (Fig. 1D-F). Although, we confirmed NKX2.2 expression in the pancreas at earlier time points (data not shown), we did not observe NKX2.2 expression in the intestine before E15.5 (Fig. 1A-C). NKX2.2 expression was seen at later embryonic time points and persisted in the adult intestine (Fig. 1G-I). In embryonic and adult intestine, NKX2.2 expression was mainly in the intervillus/crypt regions. Infrequently, we detected weak NKX2.2 expression along the villi. These observations suggest that $N k x 2.2$ is transiently expressed in immature and/or newly differentiated cells.

To determine whether $N k x 2.2$ is expressed in endocrine progenitors, we costained for NKX2.2 and NEUROG3. Approximately, 80\% of NEUROG3positive endocrine progenitor cells co-expressed NKX2.2 (Fig. 2A-D). Next, we studied the co-expression of NKX2.2 and MKI67, a marker for proliferating cells. We did not observe co-expression of NKX2.2 and MKI67, suggesting NKX2.2-positive cells have exited the cell cycle (Fig. 2E-H).

To determine whether $N k x 2.2$ is expressed in gut endocrine cells, we performed double IF analysis. The most predominant hormone in the gut is 5-HT, and we observed co-localization of NKX2.2 with 5-HT within the crypt compartment of adult intestine (Fig. 3A). We did not observe NKX2.2 expression in the villus regions, where more differentiated endocrine cells reside, as shown by the cells that were positive for 5-HT but negative for NKX2.2 (Fig. 3A). We also detected co-expression of NKX2.2 with GLP-1 (Fig. 3B), gastrin/CCK (Fig. 3C), and somatostatin (Fig. 3D) in adult intestinal crypts. Consistently, we observed NKX2.2 expression in the crypt compartment but not along the villi. Secretin 

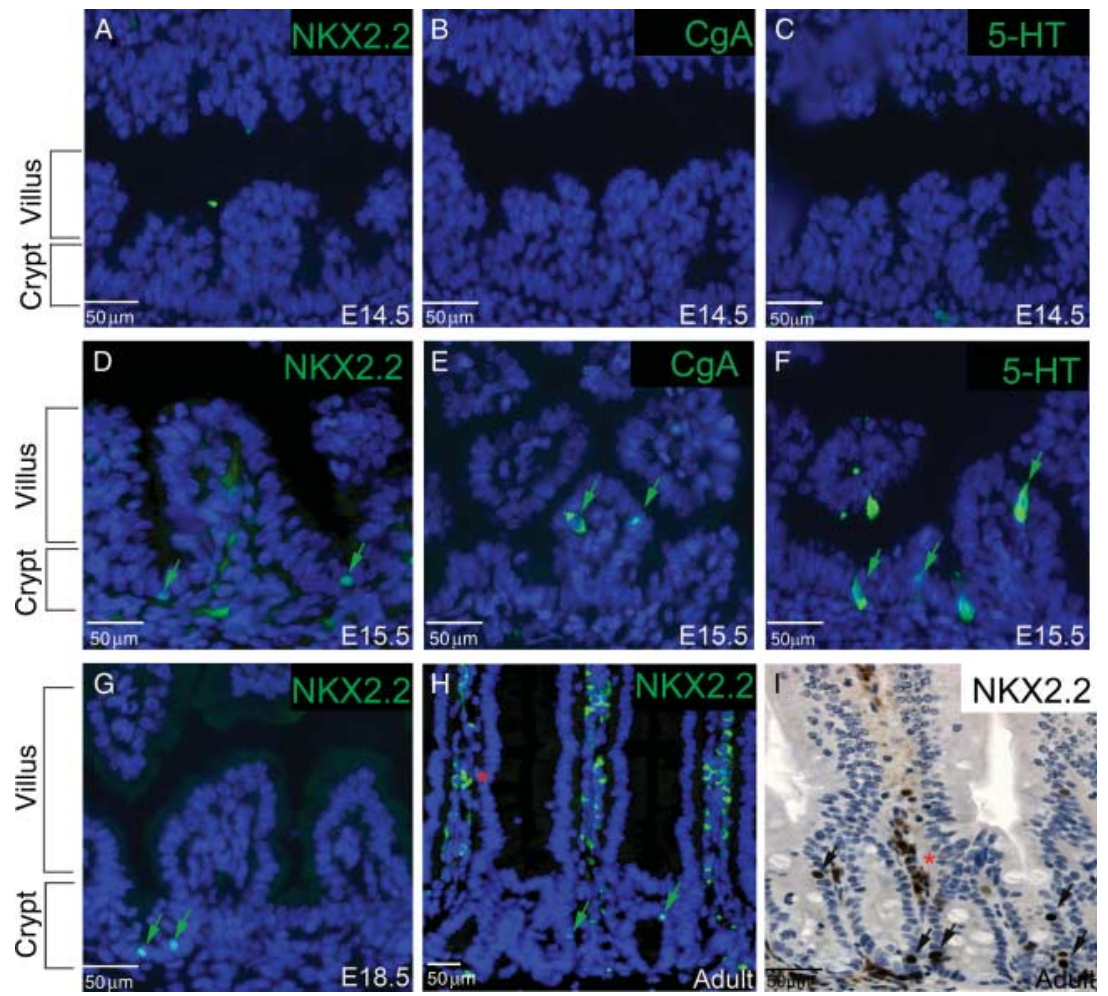

Figure $1 \mathrm{Nkx2.2}$ is expressed in embryonic and adult mouse intestine. Immunofluorescent analysis of duodenal sections of E14.5 $(A, B, C), E 15.5(D, E, F), E 18.5(G)$, and adult $(H)$ mice using the antibodies indicated. Immunohistochemistry experiment performed on a duodenal section of adult mouse (I). Onset of nuclear NKX2.2 expression coincides with the appearance of CgA- and 5-

HT-positive cells in the intestinal epithelium at E15.5 and persists in adults. NKX2.2 expression is restricted to the crypt compartment. Non-specific cytoplasmic staining of inflammatory cells in the lamina propria of adult mouse intestine $(\mathrm{H}, \mathrm{I})$ indicated by red asterisk $\left({ }^{*}\right)$.

expression is known to be restricted to the villus compartment (Aiken et al. 1994); we confirmed this observation and again found NKX2.2 expression only in the crypts (Fig. 3E). Thus, we did not detect any cells that were positive for both $N k x 2.2$ and secretin. These results suggest that in the adult intestine, NKX2.2 is transiently expressed in newly differentiated endocrine cells that produce serotonin, GLP-1, gastrin/CCK, and somatostatin.

\section{Nkx2.2 (-I-) mice display defects in intestinal endocrine cell development}

To elucidate the role of NKX2.2 in gut endocrine development, we analyzed the proximal small intestine (duodenum) in $N k x 2.2(-/-)$ mice. Since homozygous mutant animals die within 6 days of birth, we analyzed intestine from embryos at E18.5 (Sussel et al. 1998). At this time point, mutant embryos are viable and gut hormones are present. By routine H\&E staining, we did not detect any abnormalities in the appearance of $N k x 2.2(-/-)$ intestine (data not shown). We first assayed for 5-HT expression by IF analysis because 5-HT is the most abundant gut endocrine cell type. Strikingly, we observed that cells producing 5-HT were absent from the intestine of $N k x 2.2(-/-)$ mice (Fig. 4A-C). Consistent with this, mRNA levels of tryptophan hydroxylase-1 (Tphl), which catalyzes the rate-limiting step in 5-HT biosynthesis in the gut, were absent in $N k x 2.2(-/-)$ intestine as assayed by qRT-PCR (Fig. 5B).

In the small intestine, particular endocrine cell types may serve as progenitors for other endocrine cells. For example, Aiken and Roth (1992) postulated that a population of cells that express substance $P$ remain in the crypt and ultimately express 5-HT. They also suggested that another population of upwardly migrating gut endocrine cells sequentially express substance P, 5-HT, and secretin as they move from the crypt to the villus. We therefore examined the expression of tachykinin precursor 1 (Tacl) that encodes for substance P (by RT-PCR) and secretin (by RT-PCR and IF) and observed a marked decrease in the intestine of $N k x 2.2(-/-)$ compared with wildtype litter mates (Fig. 4G-I, 5A). These findings support a common differentiation pathway involving cells that produce substance $\mathrm{P}, 5-\mathrm{HT}$, and secretin. 

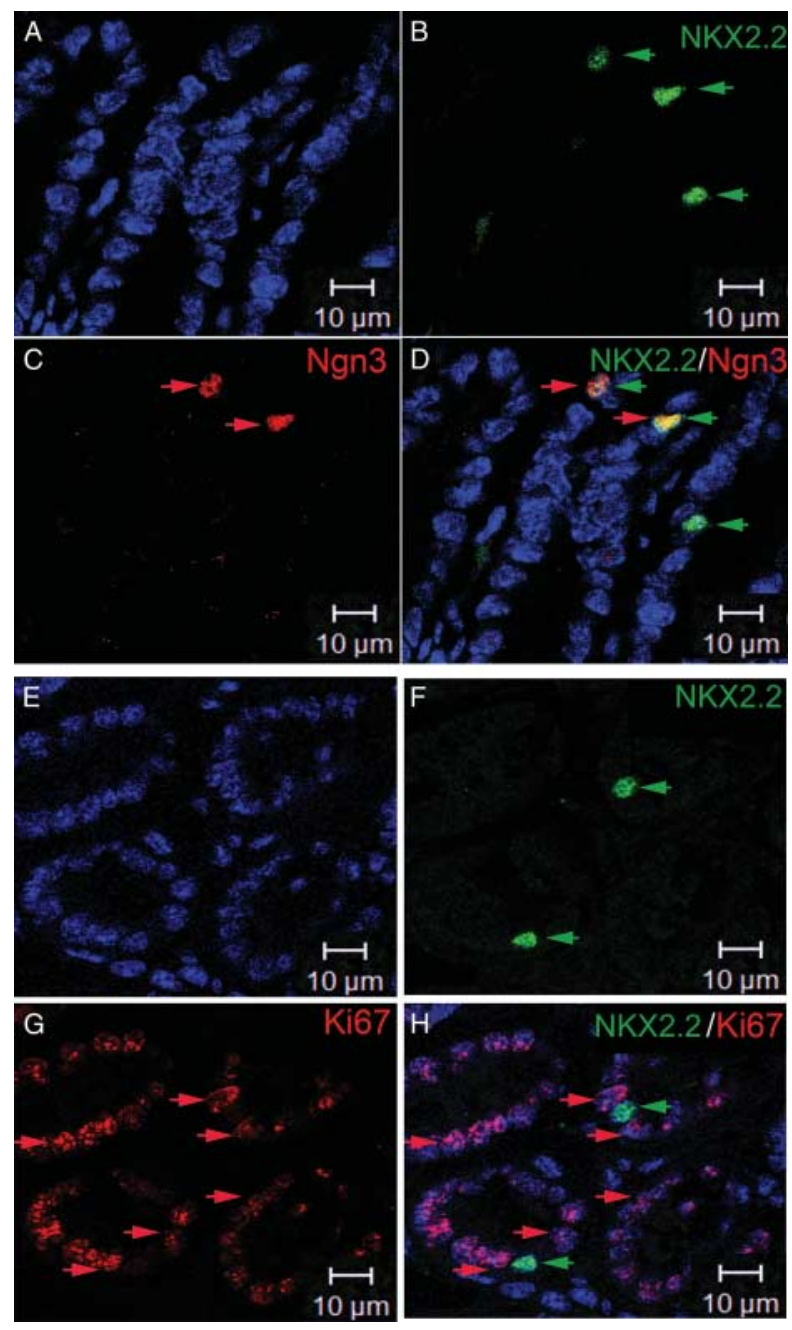

Figure 2 NKX2.2 is expressed in NEUROG3-positive endocrine precursors that have exited the cell cycle in adult mouse intestine. $(A-H)$ Immunofluorescence experiments of duodenal sections from adult mice with the antibodies indicated. (A-D) Co-expression of NKX2.2 and NEUROG3 in nuclei of cells located in the crypt compartment. (A, E) DAPI identifies nuclei. Immunofluorescent staining for NKX2.2 (B, green) and NEUROG3 (C, red) with merged image (D) showing yellow double-stained cells. (E-H) Double immunofluorescent analysis for NKX2.2 and MKI67. Immunofluorescent staining for NKX2.2 (F, green) and MKI67 (G, red) with merged image $(\mathrm{H})$ shows NKX2.2, and MKI67 that are not co-expressed, indicating NKX2.2 is expressed in non-proliferating cells.

Aiken et al. (1994) postulated that cells which express secretin might also arise from a distinct differentiation pathway for upwardly migrating cells that express gastrin, CCK, and GLP-1. In support of this postulate, we detected a decrease of cells producing gastrin/CCK and GLP-1 in the intestine of $N k x 2.2(-/-)$ mice, when compared with their $N k x 2.2(+/+)$ littermates (Fig. 4D-F). Transcript levels of gastrin, CCK, glucagon, and somatostatin were also decreased in $N k x 2.2(-/-)$ intestine (Fig. 5A). The glucagon gene encodes for preproglucagon, which undergoes post-translational processing to produce GLP-1, GLP-2, or glucagon (Rehfeld 1998).
Therefore, $N k x 2.2$ is critical for the development of several types of gut endocrine cells.

\section{Nkx2.2(-I-) mouse intestine does not exhibit defects in proliferation, increased apoptosis, or deviation to other types of gut epithelial cells}

Depletion of several gut endocrine cells in $N k x 2.2$ mutant mice may result from defects in epithelial proliferation, increased apoptosis, or deviation to an alternative cell fate. We did not observe impaired proliferation of $N k x 2.2$ mutant intestine when it was assessed by MKI67 labeling (WT $=21.3$, MUT $=$ 25.9 cells $/ \mathrm{mm} ; P=0.26)$. When we assayed for cell 


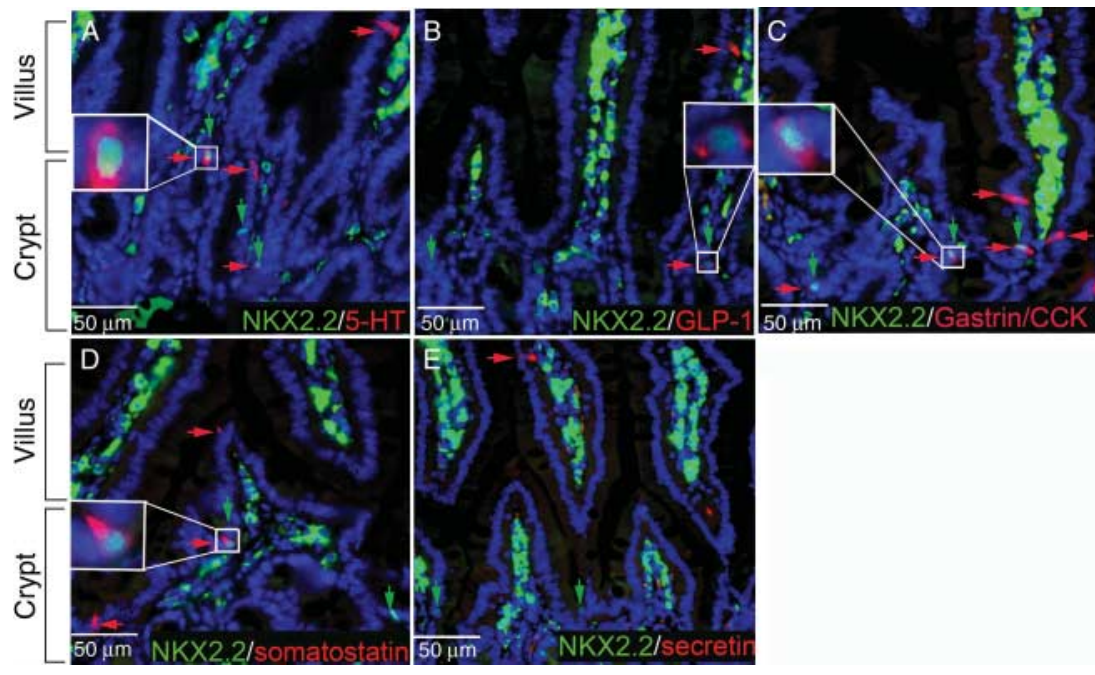

Figure $3 \mathrm{Nkx2.2}$ is co-expressed with hormones located in the intestinal crypt compartment. (A-E) Double immunofluorescence experiments on sections of duodenum from adult mice with the antibodies indicated. Nuclear expression of NKX2.2 is present in cells producing 5-HT (A), GLP-1 (B), gastrin/CCK (C), and somatostatin (D) in the crypt compartment. (E) Cells that produce secretin are present only in the villi. Expression of NKX2.2 is detected in the crypts, but not villi, indicating NKX2.2 is in newly differentiated enteroendocrine cells.

death as a cause for decreased gut endocrine populations in $N k x 2.2(-/-)$ mouse intestine by activated caspase 3 staining, we did not detect an increase in apoptosis, which was low in both wild-type and $N k x 2.2$ mutant mice $(\mathrm{WT}=0.84, \mathrm{MUT}=$ 0.10 cells $/ \mathrm{mm} ; P=0.30)$. We did not observe an increase in goblet cell numbers (WT $=23.6$, MUT $=$ 21.2 cells $/ \mathrm{mm} ; P=0.75)$ in the intestine of $N k x 2.2$ mutant mice to suggest that endocrine cells adopted a goblet cell fate in the absence of $N k x 2.2$. Moreover, expression of cryptidin, an early Paneth cell marker, or enterocyte glycoprotein distribution (assessed by FITC-conjugated WFA staining) was not altered in $N k x 2.2$ mutant intestine (data not shown).

\section{The number of ghrelin-producing cells is increased in Nkx2.2 (-I-) mouse intestine}

We observed a marked reduction in endocrine cells in $N k x 2.2(-/-)$ mouse intestine; however, we found no evidence for a decrease in proliferation, increase in apoptosis, or deviation to an alternative epithelial cell fate to explain the loss of endocrine cells. In the pancreas, $N k x 2.2$ is required for the differentiation of all $\beta$-cells, which produce insulin, as well as some cells that produce glucagon and pancreatic polypeptide (Sussel et al. 1998). In the absence of $N k x 2.2$, $\beta$-cells are replaced by ghrelin-producing cells in the pancreas (Prado et al. 2004). Moreover, Pax4 and Pax6 mutant mice exhibit a similar phenotype: a loss of $\beta$-cells with an increase in ghrelin-producing cells in the pancreas (Prado et al. 2004, Heller et al. 2005). We therefore investigated whether an increase of ghrelin-producing cells was associated with the depletion of most endocrine cell types in $N k x 2.2$ mutant intestine. We analyzed the intestine of $N k x 2.2$ mutant mice and observed a marked increase in the number of ghrelin cells (Fig. 4M-O). Concordant with the detection of increased numbers of ghrelin cells in $N k x 2.2(-/-)$ intestine, the expression of ghrelin assayed by qRT-PCR was elevated in $N k x 2.2$ mutant intestine (Fig. 5C). Potential reasons for the difference in magnitude increase in ghrelin cell number and transcript level in $N k x 2.2(-/-)$ intestine include: 1) $N k x 2.2$ loss may cause more of an increase in ghrelin transcript level than cell number; 2) differential sensitivity in the detection of ghrelin transcript level and protein by the methods used; and 3) differences in the stability of ghrelin transcript and protein. As in the pancreas (Schwitzgebel et al. 2000), NEUROG3 expression levels in $N k x 2.2(-/-)$ intestine did not differ from those in wild-type littermates when assayed by IF and qRTPCR (data not shown). Similar to its role in the pancreas, $N k x 2.2$ functions to control endocrine cell fate in the intestine.

\section{NKX2.2 expression in normal human gut tissue recapitulates that in mice}

Given the importance of $N k x 2.2$ function in the differentiation of $\mathrm{NE}$ cells in the mouse gut, we 


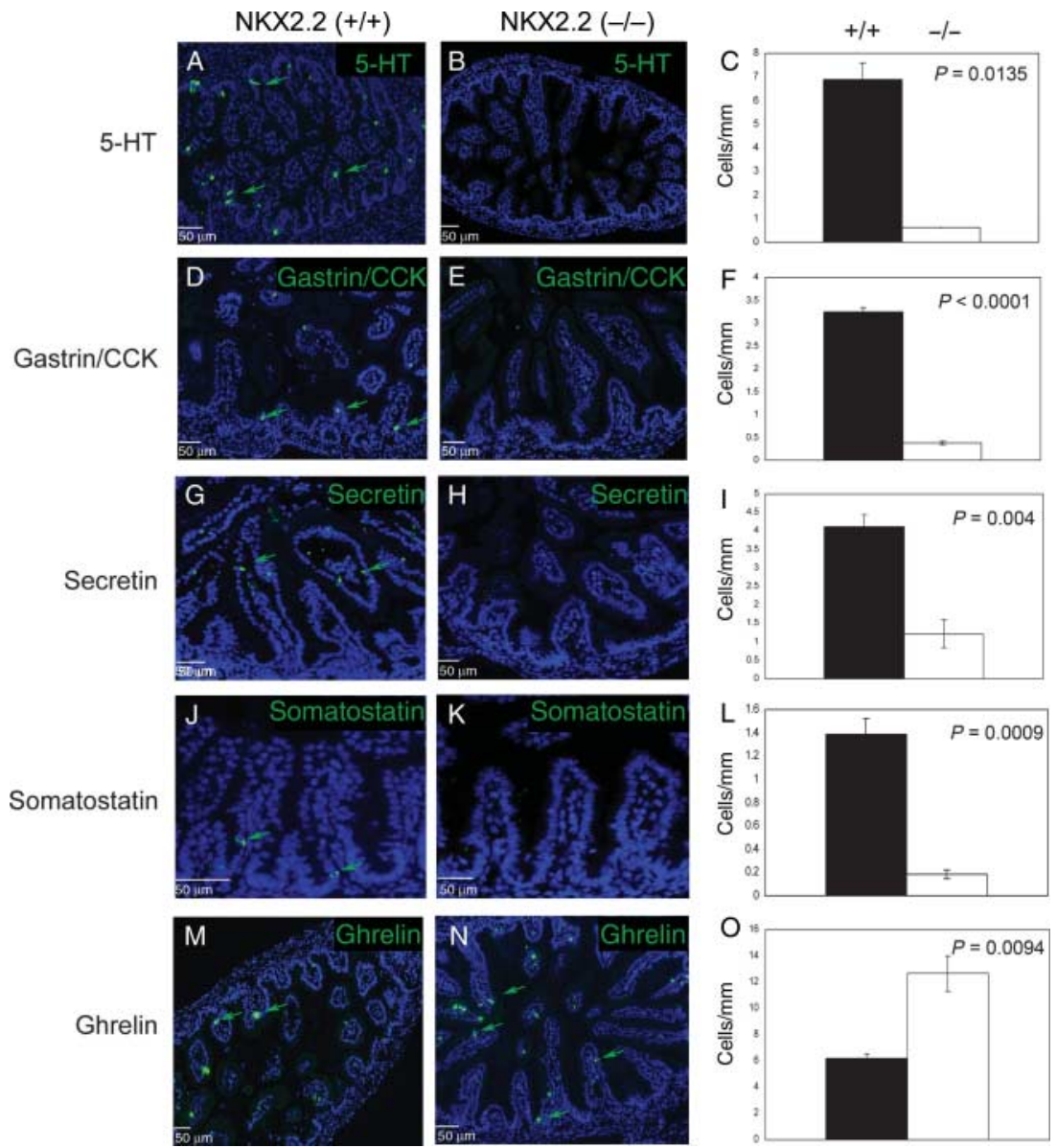

Figure $4 N k x 2.2$ regulates enteroendocrine development. Immunofluorescence analysis of duodenal sections of control (A, D, G, J, $\mathrm{M})$ or $N k x 2.2(-/-)(\mathrm{B}, \mathrm{E}, \mathrm{H}, \mathrm{K}, \mathrm{N})$ mouse embryos at E18.5 with the antibodies indicated. In $N k x 2.2(+/+)$ intestine, 5-HT $(\mathrm{A})$, gastrin/CCK (D), secretin (G), somatostatin (J), and ghrelin (M) are observed in characteristic patterns. There is a near absence of 5-HT (B), gastrin/CCK (E), secretin (H), and somatostatin (K) expression in Nkx2.2 $(-/-)$ intestine. Conversely, ghrelin (N) expression is increased in $N k x 2.2(-/-)$ intestine. $(C, F, I, L, O)$ Results of immunofluorescence experiments presented quantitatively. The number of hormone-positive cells per mm intestinal length of every fourth section of $N k x 2.2(+/+)(n=3)$ and Nkx2.2 $(-/-)(n=3)$ intestine was counted. Results represent mean \pm S.E.M.

evaluated NKX2.2 expression in human gut tissues. Using immunohistochemistry (IHC), we detected strong NKX2.2 expression in the nuclei of islets in normal human adult pancreas (Fig. 6A). As in adult mice (Sussel et al. 1998), we did not observe NKX2.2 expression in pancreatic exocrine tissue. In normal human adult small intestine, NKX2.2 protein is present in cells located in the crypt compartment (Fig. 6B and C). Infrequently, we detected weak NKX2.2 expression in cells located in the villi; however, the intensity of NKX2.2 expression in the villi was always much less than in the crypts. Therefore, the pattern of NKX2.2 expression in normal human adult pancreas and small intestine resembles that found in mice, suggesting a conserved role for NKX2.2 in NE differentiation in mouse and human gut.

\section{NKX2.2 expression in human gut NE tumors}

Because conserved pathways of NE differentiation function in normal and neoplastic tissues (Borges et al. 1997, Nakakura et al. 2001), we evaluated NKX2.2 expression in human NE tumors derived from the gut. Using qRT-PCR, we analyzed NKX2.2 expression in matched pairs of normal and tumor samples from patients with well-differentiated NE tumors of the ileum $(n=4)$ and pancreas $(n=2)$. When compared with matched normal ileum samples, NE tumors of the ileum (three primary ileum tumors and one liver metastasis) showed an approximately 20- to 200-fold increase in $N K X 2.2$ expression (Fig. 6O). In addition, we observed about a 9- to 900-fold increase in NKX2.2 expression in pancreas NE tumor samples when 

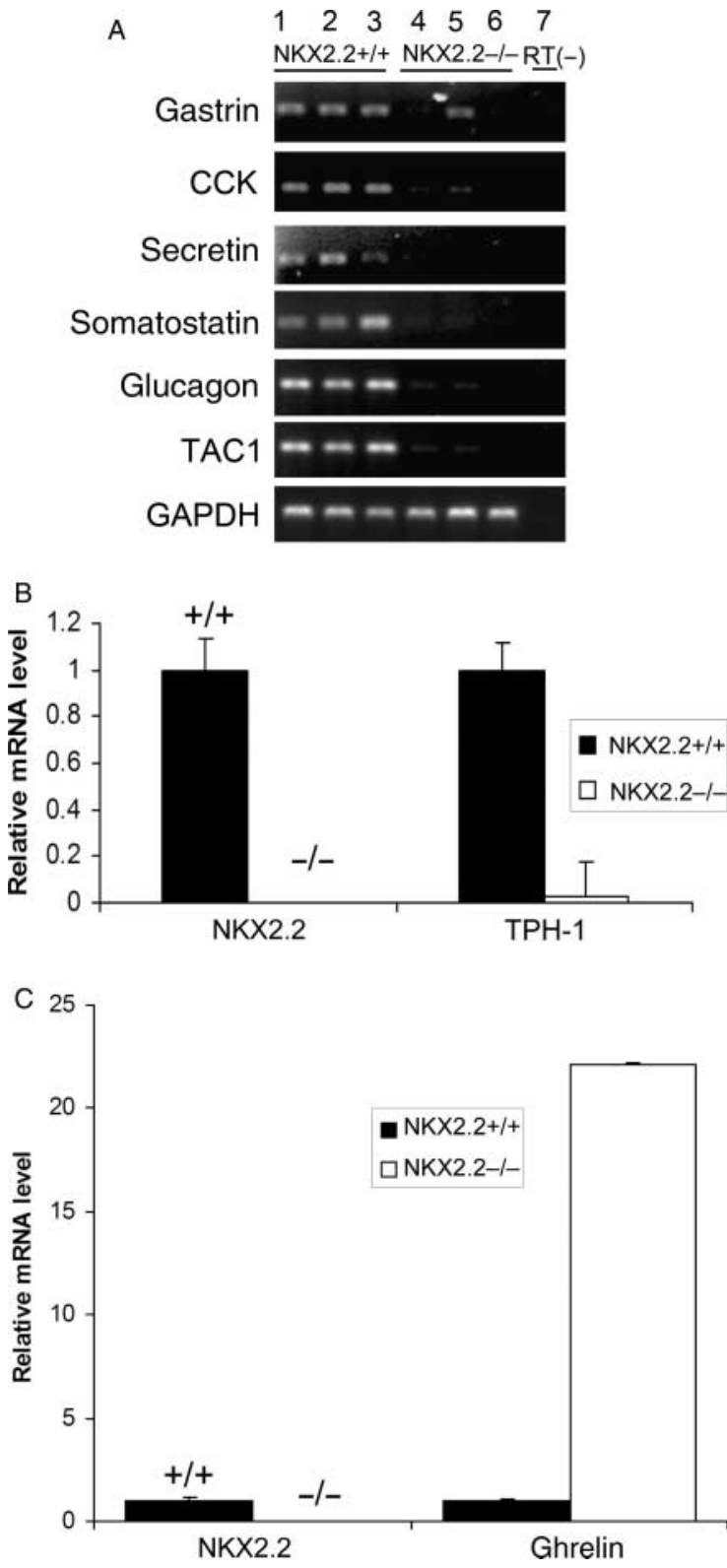

Figure 5 Expression of hormones in Nkx2.2(+/+) and Nkx2.2 $(-/-)$ intestine assayed by RT-PCR. Expression of the indicated genes in the duodenum of $N k \times 2.2(+/+)(n=3)$ and Nkx2.2 $(-/-)(n=3)$ mouse embryos at E18.5 by semiquantitative RT-PCR (A) or real-time TaqMan RT-PCR (B, C). Compared with $N k x 2.2(+/+)$ intestine (A, lanes 1, 2, 3), near absence of expression of gastrin, CCK, secretin, somatostatin, glucagon, and Tac1 is observed in Nkx2.2 (-/-) intestine (A, lanes 4, 5, 6). No reverse transcriptase was used (A, lane 7). Expression of $N k x 2.2$ is not detectable in $N k x 2.2(-/-)$ intestine (B, C). In Nkx2.2 (-/-) intestine, near absence of Tph-1 (B) expression but dramatic increase in ghrelin (C) expression is observed. Expression of each gene in Nkx2.2 $(+/+)$ is set at 1.0 , and levels in $N k x 2.2(-/-)$ relative to that in $N k x 2.2(+/+)$ are shown. Results represent mean \pm S.E.M. compared with matched normal pancreas tissue (Fig. 6P). These findings indicate that $N K X 2.2$ is expressed in NE tumors derived from the gut, which may reflect utilization of a common pathway of NE differentiation in normal and neoplastic tissues.

To further evaluate $N K X 2.2$ expression in human tumors, we used IHC to detect NKX2.2 protein in a variety of well-differentiated NE tumors found throughout the gut. Overall, we detected nuclear expression of NKX2.2 in 83\% (24/29) of human NE tumor samples (Table 1). Specifically, NKX2.2 was present in NE tumors of the stomach (1/1), duodenum (1/1), ampulla of Vater (2/2), pancreas (14/16; Fig. 6D), ileum (5/5; Fig. 6H), and colon (1/1). NKX2.2 was detected in both functioning and nonfunctioning NE tumors. Interestingly, NKX2.2 was not present in NE tumors of the bronchus (0/3; Fig. 6L). For the five NE tumor specimens (two pancreas, three bronchus) in which we did not observe Nxk2.2 expression by IHC, NE markers (CgA, synaptophysin) and/or hormones were present. Because robust NKX2.2 expression is readily detected by IHC in most human NE tumors from diverse GI primary sites, we conclude that NKX2.2 is a novel GI NE tumor marker.

\section{Discussion}

In the present study, we show that the homeodomain transcription factor NKX2.2 functions in immature endocrine cells to control NE differentiation in mouse intestine and is expressed in most human GI NE tumors derived from diverse primary sites. We also show that NKX2.2 is expressed in normal human pancreas and intestine in a similar distribution as in mice, supporting the use of the mouse as a model for studying NE differentiation in the human gut. Together, our findings suggest a conserved role for NKX2.2 in NE differentiation of normal and neoplastic gut.

We are the first to report that NKX2.2 expression is restricted to the intervillus/crypt regions of embryonic and adult mouse intestine, where it is co-expressed in NEUROG3-positive endocrine progenitors and newly differentiated endocrine cells. The presence of NKX2.2 in immature endocrine cells is consistent with our finding that $N k x 2.2$ functions to control endocrine cell fate in the intestine. Our analysis of $N k x 2.2(-/-)$ mouse intestine suggests $N k x 2.2$ functions downstream of Neurog3 to control the development of numerous endocrine cells. In the intestine of $N k x 2.2(-/-)$ mice, Neurog 3 expression was unaffected, and we observed a dramatic reduction in the number of cells producing numerous hormones, such as serotonin, gastrin, CCK, 

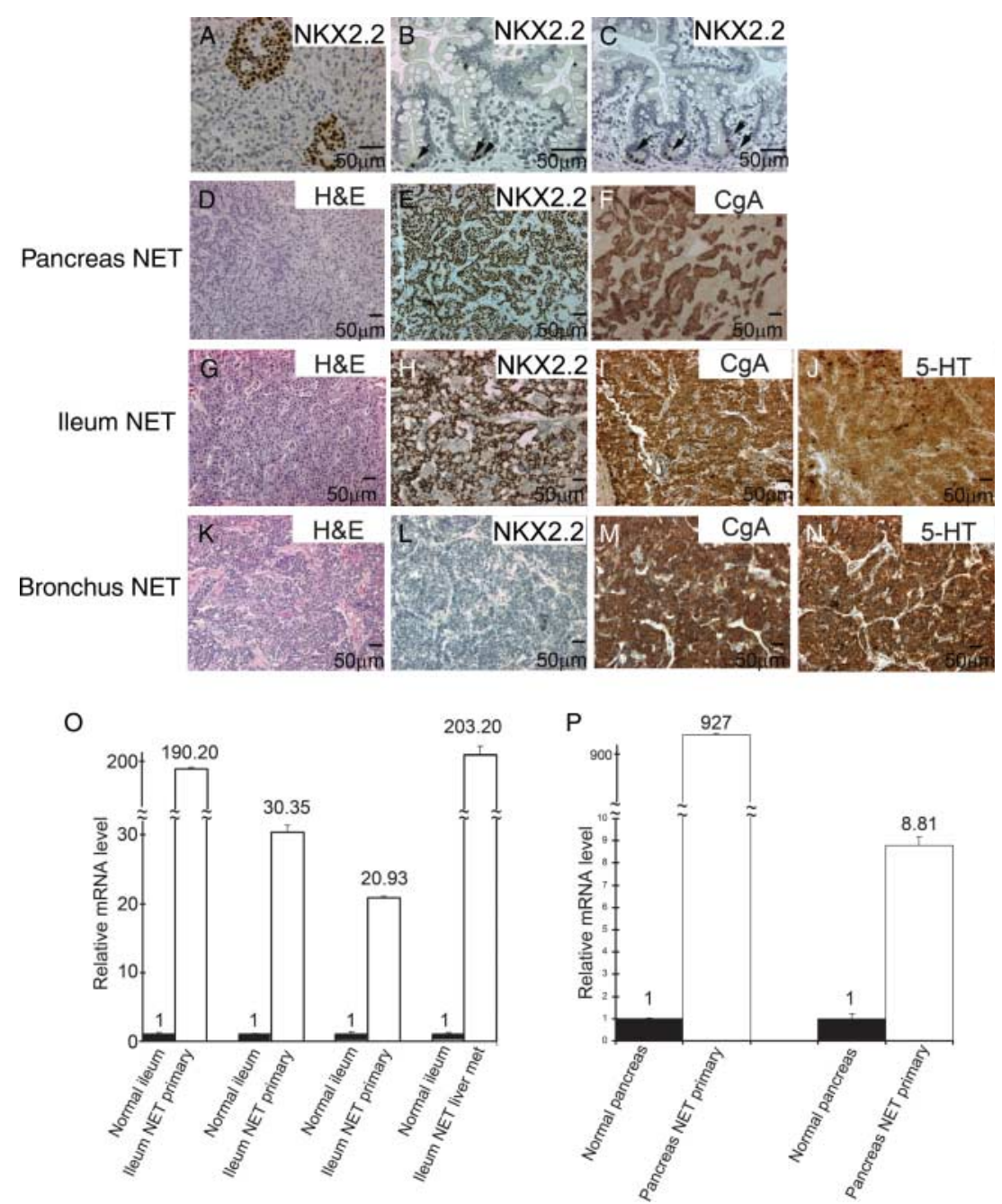

Figure 6 NKX2.2 is expressed in normal and neoplastic human pancreas and intestine. (A-N) Sections of normal adult human tissues and well-differentiated NE tumors are stained with H\&E or with the antibodies indicated for immunohistochemistry.

(A) Nuclear NKX2.2 expression is detected in normal human adult pancreatic islets. $(B, C)$ In normal human adult ileum, nuclear NKX2.2 expression is seen in the crypt compartment but not in the villi. Abundant NKX2.2 protein is present in the nuclei of NE tumors of the pancreas $(E)$ and ileum $(H)$, but not bronchus $(L) . C g A(F, I, M)$, and $5-H T(J, N)$ are in the cytoplasm of NE tumors. $(\mathrm{O}, \mathrm{P})$ Real-time TaqMan RT-PCR analysis of NKX2.2 expression in matched normal tissue and NE tumors derived from the ileum and pancreas. NKX2.2 is expressed in NE tumors of the ileum $(O)$ and pancreas $(P)$. Expression level of NKX2.2 in matched normal tissue is set at 1.0, and levels in NE tumor relative to that in matched normal tissue are shown. Results represent mean \pm S.E.M.

somatostatin, GLP-1, substance P, and secretin, but an increase in cells producing ghrelin. These data suggest that endocrine cells in the intestine arise from a common progenitor and that $N k x 2.2$ acts to specify or maintain the expression of numerous hormones.

The study reported herein expands on and is consistent with that of Desai et al. (2008). Desai et al. (2008) showed that $N k x 2.2$ regulates endocrine cell fate in the small intestine and is expressed in glucagon-producing cells. Our study is the first to show that NKX2.2 expression is restricted to immature endocrine cells located in the intestinal crypts. In particular, we observed that $N k x 2.2$ expression is limited to NEUROG3-positive endocrine progenitors and newly-differentiated endocrine cells, producing numerous hormones, such as 5-HT, gastrin/CCK, somatostatin, and GLP-1. Importantly, our study reveals several new aspects of $N K X 2.2$ expression in neoplastic as well as normal gut. We are the first to show NKX2.2 is expressed in the majority of $\mathrm{NE}$ tumors derived from the gut. In particular, $N K X 2.2$ expression was detected in NE tumors of the stomach, duodenum, ampulla of Vater, pancreas, ileum, and colon. In support of our observations, NKX2.2 is 
Table 1 Immunohistochemical analysis of NKX2.2, CgA, and Syn expression in NE tumors of the gut

\begin{tabular}{|c|c|c|c|c|c|c|}
\hline & Primary site & NKX2.2 IHC & CgA IHC & Syn IHC & $\begin{array}{l}\text { Functioning/ } \\
\text { non-functioning }\end{array}$ & Hormones/syndrome \\
\hline 1 & Stomach & $4+$ & Positive & Negative & NF & \\
\hline 2 & $\begin{array}{c}\text { Duodenum (LN } \\
\text { metastasis) }\end{array}$ & $4+$ & Positive & ND & $\mathrm{F}$ & Gastrinoma \\
\hline 3 & Ampulla & $4+$ & Positive & Positive & NF & 5-HT \\
\hline 4 & Ampulla & $4+$ & Positive & Positive & NF & $5-\mathrm{HT}$ \\
\hline 5 & Pancreas & 0 & Positive & Positive & $\mathrm{F}$ & Insulinoma \\
\hline 6 & Pancreas & 0 & Positive & Positive & NF & Glucagon, VIP \\
\hline 7 & $\begin{array}{c}\text { Pancreas (liver } \\
\text { metastasis) }\end{array}$ & $2+$ & Positive & Positive & $\mathrm{F}$ & Glucagonoma \\
\hline 8 & $\begin{array}{c}\text { Pancreas (liver } \\
\text { metastasis) }\end{array}$ & $4+$ & Positive & Positive & NF & \\
\hline 9 & Pancreas & $4+$ & Positive & Positive & $\mathrm{F}$ & Gastrinoma, MEN I \\
\hline 10 & Pancreas & $4+$ & Positive & ND & NF & $5-\mathrm{HT}$ \\
\hline 11 & Pancreas & $4+$ & Positive & ND & $\mathrm{F}$ & Insulinoma \\
\hline 12 & Pancreas & $4+$ & Positive & Positive & NF & \\
\hline 13 & Pancreas & $4+$ & Positive & Positive & $\mathrm{F}$ & Insulinoma \\
\hline 14 & Pancreas & $4+$ & Positive & Positive & NF & \\
\hline 15 & Pancreas & $4+$ & Positive & Positive & NF & \\
\hline 16 & Pancreas & $4+$ & Positive & Positive & NF & \\
\hline 17 & Pancreas & $4+$ & Positive & Positive & NF & \\
\hline 18 & Pancreas & $4+$ & Positive & Positive & NF & \\
\hline 19 & Pancreas & $4+$ & Positive & Positive & NF & \\
\hline 20 & Pancreas & $4+$ & Positive & Positive & NF & MEN I (HPT) \\
\hline 21 & Ileum & $2+$ & ND & ND & $\mathrm{F}$ & Carcinoid syndrome \\
\hline 22 & Ileum & $3+$ & Positive & Positive & NF & \\
\hline 23 & Ileum & $3+$ & ND & ND & $\mathrm{F}$ & Carcinoid syndrome \\
\hline 24 & Ileum & $3+$ & Positive & Positive & $\mathrm{F}$ & Carcinoid syndrome \\
\hline 25 & $\begin{array}{l}\text { Ileum (liver } \\
\text { metastasis) }\end{array}$ & $3+$ & ND & ND & NF & \\
\hline 26 & Colon & $4+$ & Positive & Positive & NF & \\
\hline 27 & Bronchus & 0 & Positive & positive & NF & $5-\mathrm{HT}$ \\
\hline 28 & Bronchus & 0 & Positive & ND & NF & \\
\hline 29 & Bronchus & 0 & Positive & Positive & NF & $\begin{array}{l}\text { 5-HT/MEN I } \\
\text { (pituitary adenoma, HPT, } \\
\text { gastrinoma of pancreas } \\
\text { and duodenum) }\end{array}$ \\
\hline
\end{tabular}

$\mathrm{CgA}$, chromogranin A; Syn, synaptophysin; IHC, immunohistochemistry; LN, lymph node; NF, non-functioning; F, functioning; MENI, multiple endocrine neoplasia I; HPT, hyperparathyroidism; 5-HT, serotonin; ND, not done.

present on chromosome 20p11, and amplification of chromosome $20 \mathrm{p}$ is a frequent allelic alteration in welldifferentiated NE tumors of the gut (Kim et al. 2008).

Conserved pathways of NE differentiation function in diverse contexts. In normal tissues, the basic helixloop-helix transcription factor ASCl1 functions in the development of neurons producing 5-HT, pulmonary NE cells, and thyroid C cells (Blaugrund et al. 1996, Borges et al. 1997, Lanigan et al. 1998, Pattyn et al. 2004). Studies have also suggested ASCl1 regulates the NE phenotype in cancers of many sites: brain, thyroid, lung, prostate, and GI tract (Borges et al. 1997, Hu et al. 2004, Nakakura et al. 2005, Shida et al. 2005, Somasundaram et al. 2005, Kunnimalaiyaan et al.
2006, Rousseau et al. 2006). Evidence also suggests that ASCl1 may promote tumorigenesis (Linnoila et al. 2000, Osada et al. 2005). NKX2.2 functions with ASCl1 in 5-HT neuron development (Briscoe et al. 1999, Cheng et al. 2003, Craven et al. 2004, Pattyn et al. 2004). Recently, NKX2.2 has been shown to promote tumorigenesis in Ewing's sarcomas (Smith et al. 2006). These previous studies in conjunction with the data presented herein demonstrate that NKX2.2 is involved in both normal and neoplastic development, and it is tempting to speculate that NKX2.2 might act with ASC1 in these contexts. Transcription factors, such as NKX2.2 and ASC11, may exhibit dual functions: 1) to regulate NE differentiation and 
2) to promote tumorigenesis. Therefore, the study of the determinants of $\mathrm{NE}$ differentiation in normal development has the potential to provide important insights into NE tumor biology and vice versa.

Elucidating the transcription factors that maintain the NE phenotype in tumors and their regulation by signaling pathways has the potential to directly impact patient morbidity and mortality. Functioning NE tumors, by definition, produce debilitating symptoms due to the elaboration of hormones (Nakakura \& Bergsland 2007, Nakakura et al. 2007, Modlin et al. 2008). Hormones such as serotonin also stimulate NE tumor growth via autocrine and paracrine stimulatory loops (Ishizuka et al. 1992, von Wichert et al. 2000). We and others have previously shown that Notch signaling inhibits ASCl1, NE marker, and hormone expression, as well as growth, in a variety of $\mathrm{NE}$ tumors (Kunnimalaiyaan et al. 2005, 2006, Nakakura et al. 2005). As a result, pharmacological activators of Notch signaling, such as valproic acid, are being evaluated in clinical trials for patients with advanced NE tumors (Greenblatt et al. 2007a,b). The effect of Notch signaling on NKX2.2 expression in NE tumors is not known; however, in the developing intestine, the absence of the Notch effector, Hes1, leads to increased NKX2.2 expression, suggesting NKX2.2 is a Notch target in normal intestinal epithelium (Jensen et al. $2000 b$ ). It is plausible that targeting NKX2.2 in NE tumors might actually worsen the biology by causing dedifferentiation to a poorly differentiated NE carcinoma. Further studies of NKX2.2 and other transcriptions factors with conserved functions in normal and neoplastic tissues are likely to provide new insights into NE tumor biology that can be exploited to better treat patients.

\section{Declaration of interest}

There is no conflict of interest that could be perceived as prejudicing the impartiality of the research reported.

\section{Funding}

This work was supported by the James Ewing Oncology Fellowship Award (to E K N), American College of Surgeons Faculty Research Fellowship (to E K N), University of California Cancer Research Coordinating Committee funds (to E K N), UCSF Research Evaluation and Allocation Committee (REAC) Grant (to E K N), Novartis Oncology provided through the CALGB Foundation (to $\mathrm{E} \mathrm{K} \mathrm{N}$ ), and The V Foundation for Cancer Research (to E K B, E K N).

\section{Acknowledgements}

We thank Eva Soliven and the UCSF Mouse Pathology Core for help with tissue processing and Pamela Derish for editorial assistance.

\section{References}

Aiken KD \& Roth KA 1992 Temporal differentiation and migration of substance $\mathrm{P}$, serotonin, and secretin immunoreactive enteroendocrine cells in the mouse proximal small intestine. Developmental Dynamics 194 303-310.

Aiken KD, Kisslinger JA \& Roth KA 1994 Immunohistochemical studies indicate multiple enteroendocrine cell differentiation pathways in the mouse proximal small intestine. Developmental Dynamics 201 63-70.

Blaugrund E, Pham TD, Tennyson VM, Lo L, Sommer L, Anderson DJ \& Gershon MD 1996 Distinct subpopulations of enteric neuronal progenitors defined by time of development, sympathoadrenal lineage markers and Mash-1-dependence. Development 122 309-320.

Borges M, Linnoila RI, van de Velde HJ, Chen H, Nelkin BD, Mabry M, Baylin SB \& Ball DW 1997 An achaete-scute homologue essential for neuroendocrine differentiation in the lung. Nature 386 852-855.

Briscoe J, Sussel L, Serup P, Hartigan-O'Connor D, Jessell TM, Rubenstein JL \& Ericson J 1999 Homeobox gene NKX2.2 and specification of neuronal identity by graded Sonic hedgehog signalling. Nature 398 622-627.

Cheng L, Chen CL, Luo P, Tan M, Qiu M, Johnson R \& Ma QL 2003 Lmx1b, Pet-1, and NKX2.2 coordinately specify serotonergic neurotransmitter phenotype. Journal of Neuroscience 23 9961-9967.

Craven SE, Lim KC, Ye W, Engel JD, de Sauvage F \& Rosenthal A 2004 Gata2 specifies serotonergic neurons downstream of sonic hedgehog. Development 131 1165-1173.

Creutzfeldt W 1994 Historical background and natural history of carcinoids. Digestion 3 (Suppl 3) 3-10.

Desai S, Loomis Z, Pugh-Bernard A, Schrunk J, Doyle MJ, Minic A, McCoy E \& Sussel L 2008 NKX2.2 regulates cell fate choice in the enteroendocrine cell lineages of the intestine. Developmental Biology 313 58-66.

Greenblatt DY, Cayo M, Ning L, Jaskula-Sztul R, Haymart M, Kunnimalaiyaan M \& Chen H 2007a Suberoyl bishydroxamic acid inhibits cellular proliferation by inducing cell cycle arrest in carcinoid cancer cells. Journal of Gastrointestinal Surgery 11 1515-1520.

Greenblatt DY, Vaccaro AM, Jaskula-Sztul R, Ning L, Haymart M, Kunnimalaiyaan M \& Chen H 2007 b Valproic acid activates notch-1 signaling and regulates the neuroendocrine phenotype in carcinoid cancer cells. Oncologist 12 942-951.

Heller RS, Jenny M, Collombat P, Mansouri A, Tomasetto C, Madsen OD, Mellitzer G, Gradwohl G \& Serup P 2005 Genetic determinants of pancreatic epsilon-cell development. Developmental Biology 286 217-224. 
$\mathrm{Hu}$ Y, Wang T, Stormo GD \& Gordon JI 2004 RNA interference of achaete-scute homolog 1 in mouse prostate neuroendocrine cells reveals its gene targets and DNA binding sites. PNAS 101 5559-5564.

Ishizuka J, Beauchamp RD, Townsend CM Jr, Greeley GH Jr \& Thompson JC 1992 Receptor-mediated autocrine growth-stimulatory effect of 5-hydroxytryptamine on cultured human pancreatic carcinoid cells. Journal of Cellular Physiology 150 1-7.

Jenny M, Uhl C, Roche C, Duluc I, Guillermin V, Guillemot F, Jensen J, Kedinger M \& Gradwohl G 2002 Neurogenin 3 is differentially required for endocrine cell fate specification in the intestinal and gastric epithelium. EMBO Journal 21 6338-6347.

Jensen J, Heller RS, Funder-Nielsen T, Pedersen EE, Lindsell C, Weinmaster G, Madsen OD \& Serup P $2000 a$ Independent development of pancreatic alpha- and betacells from neurogenin3-expressing precursors: a role for the notch pathway in repression of premature differentiation. Diabetes 49 163-176.

Jensen J, Pedersen EE, Galante P, Hald J, Heller RS, Ishibashi M, Kageyama R, Guillemot F, Serup P \& Madsen OD 2000 $b$ Control of endodermal endocrine development by Hes-1. Nature Genetics 24 36-44.

Kim DH, Nagano Y, Choi I, White JA, Yao JC \& Rashid A 2008 Allelic alterations in well-differentiated neuroendocrine tumors (carcinoid tumors) identified by genome-wide single nucleotide polymorphism analysis and comparison with pancreatic endocrine tumors. Genes, Chromosomes and Cancer 47 84-92.

Kulke M \& Mayer R 1999 Carcinoid tumors. New England Journal of Medicine 340 858-868.

Kunnimalaiyaan M, Traeger K \& Chen H 2005 Conservation of the Notch1 signaling pathway in gastrointestinal carcinoid cells. American Journal of Physiology. Gastrointestinal and Liver Physiology 289 G636-G642.

Kunnimalaiyaan M, Vaccaro AM, Ndiaye MA \& Chen H 2006 Overexpression of the NOTCH1 intracellular domain inhibits cell proliferation and alters the neuroendocrine phenotype of medullary thyroid cancer cells. Journal Biological Chemistry 281 39819-39830.

Lanigan TM, DeRaad SK \& Russo AF 1998 Requirement of the MASH-1 transcription factor for neuroendocrine differentiation of thyroid C cells. Journal of Neurobiology 34 126-134.

Lee CS, Perreault N, Brestelli JE \& Kaestner KH 2002 Neurogenin 3 is essential for the proper specification of gastric enteroendocrine cells and the maintenance of gastric epithelial cell identity. Genes and Development 16 1488-1497.

Linnoila RI, Zhao B, DeMayo JL, Nelkin BD, Baylin SB, DeMayo FJ \& Ball DW 2000 Constitutive achaete-scute homologue-1 promotes airway dysplasia and lung neuroendocrine tumors in transgenic mice. Cancer Research 60 4005-4009.

Maggard MA, O’Connell JB \& Ko CY 2004 Updated population-based review of carcinoid tumors. Annals of Surgery 240 117-122.
Modlin IM, Oberg K, Chung DC, Jensen RT, de Herder WW, Thakker RV, Caplin M, Delle Fave G, Kaltsas GA, Krenning EP et al. 2008 Gastroenteropancreatic neuroendocrine tumours. Lancet Oncology 9 61-72.

Nakakura EK \& Bergsland EK 2007 Islet cell carcinoma: neuroendocrine tumors of the pancreas and periampullary region. Hematology/Oncology Clinics of North America 21 457-473.

Nakakura EK, Watkins DN, Schuebel KE, Sriuranpong V, Borges MW, Nelkin BD \& Ball DW 2001 Mammalian scratch: a neural-specific snail family transcriptional repressor. PNAS 98 4010-4015.

Nakakura EK, Sriuranpong VR, Kunnimalaiyaan M, Hsiao EC, Schuebel KE, Borges MW, Jin N, Collins BJ, Nelkin BD, Chen H \& Ball DW 2005 Regulation of neuroendocrine differentiation in gastrointestinal carcinoid tumor cells by notch signaling. Journal of Clinical Endocrinology and Metabolism 90 4350-4356.

Nakakura EK, Venook AP \& Bergsland EK 2007 Systemic and regional nonsurgical therapy - what is the optimal strategy for metastatic neuroendocrine cancer? Surgical Oncology Clinics of North America 16 639-651.

Ng AN, de Jong-Curtain TA, Mawdsley DJ, White SJ, Shin J, Appel B, Dong PD, Stainier DY \& Heath JK 2005 Formation of the digestive system in zebrafish: III. Intestinal epithelium morphogenesis. Developmental Biology 286 114-135.

Osada H, Tatematsu Y, Yatabe Y, Horio Y \& Takahashi 2005 ASH1 gene is a specific therapeutic target for lung cancers with neuroendocrine features. Cancer Research 65 10680-10685.

Pattyn A, Simplicio N, van Doorninck JH, Goridis C, Guillemot F \& Brunet JF 2004 Ascl1/Mash1 is required for the development of central serotonergic neurons. Nature Neuroscience 7 589-595.

Prado CL, Pugh-Bernard AE, Elghazi L \& Sosa-Pineda B 2004 Ghrelin cells replace insulin-producing beta cells in two mouse models of pancreas development. PNAS 101 2924-2929.

Rehfeld JF 1998 The new biology of gastrointestinal hormones. Physiological Reviews 78 1087-1108.

Rousseau A, Nutt CL, Betensky RA, Iafrate AJ, Han M, Ligon KL, Rowitch DH \& Louis DN 2006 Expression of oligodendroglial and astrocytic lineage markers in diffuse gliomas: use of YKL-40, ApoE, ASCL1, and NKX2-2. Journal of Neuropathology and Experimental Neurology 65 1149-1156.

Schonhoff SE, Giel-Moloney M \& Leiter AB $2004 a$ Minireview: development and differentiation of gut endocrine cells. Endocrinology 145 2639-2644.

Schonhoff SE, Giel-Moloney M \& Leiter AB $2004 b$ Neurogenin 3-expressing progenitor cells in the gastrointestinal tract differentiate into both endocrine and non-endocrine cell types. Developmental Biology $270443-454$. 
Schwitzgebel VM, Scheel DW, Conners JR, Kalamaras J, Lee JE, Anderson DJ, Sussel L, Johnson JD \& German MS 2000 Expression of neurogenin3 reveals an islet cell precursor population in the pancreas. Development 127 3533-3542.

Shida T, Furuya M, Nikaido T, Kishimoto T, Koda K, Oda K, Nakatani Y, Miyazaki M \& Ishikura H 2005 Aberrant expression of human achaete-scute homologue gene 1 in the gastrointestinal neuroendocrine carcinomas. Clinical Cancer Research 11 450-458.

Smith R, Owen LA, Trem DJ, Wong JS, Whangbo JS, Golub TR \& Lessnick SL 2006 Expression profiling of EWS/FLI identifies NKX2.2 as a critical target gene in Ewing's sarcoma. Cancer Cell 9 405-416.

Somasundaram K, Reddy SP, Vinnakota K, Britto R, Subbarayan M, Nambiar S, Hebbar A, Samuel C, Shetty M, Sreepathi HK et al. 2005 Upregulation of
ASCL1 and inhibition of Notch signaling pathway characterize progressive astrocytoma. Oncogene $\mathbf{2 4}$ 7073-7083.

Sussel L, Kalamaras J, Hartigan-O'Connor DJ, Meneses JJ, Pedersen RA, Rubenstein JL \& German MS 1998 Mice lacking the homeodomain transcription factor NKX2.2 have diabetes due to arrested differentiation of pancreatic beta cells. Development 125 2213-2221.

von Wichert G, Jehle PM, Hoeflich A, Koschnick S, Dralle H, Wolf E, Wiedenmann B, Boehm BO, Adler G \& Seufferlein T 2000 Insulin-like growth factor-I is an autocrine regulator of chromogranin A secretion and growth in human neuroendocrine tumor cells. Cancer Research 60 4573-4581.

Wilson A \& Radtke F 2006 Multiple functions of Notch signaling in self-renewing organs and cancer. FEBS Letters 580 2860-2868. 